\title{
Aplicación de un modelo geográfico con información climática para el cálculo del balance hídrico de la comarca de la Marina Baja (Alicante)
}

\author{
Benito Zaragozí Zaragozí \\ Alfredo Ramón Morte \\ Jorge Olcina Cantos \\ Universidad de Alicante. Instituto Interuniversitario de Geografía \\ benito.zaragozi@ua.es \\ alfredo.ramon@ua.es \\ jorge.olcina@ua.es
}

Recepción: octubre de 2014

Aceptación: abril de 2015

\section{Resumen}

Este trabajo analiza las nuevas tendencias en la creación y gestión de información geográfica, para la elaboración de modelos inductivos basados exclusivamente en bases de datos geográficas. Estos modelos permiten integrar grandes volúmenes de datos de características heterogéneas, lo que supone una gran complejidad técnica y metodológica. Se propone una metodología que permite conocer detalladamente la distribución de los recursos hídricos naturales en un territorio y derivar numerosas capas de información que puedan ser incorporadas a estos modelos «ávidos de datos» (data-hungry). La zona de estudio escogida para aplicar esta metodología es la comarca de la Marina Baja (Alicante), para la que se presenta un cálculo del balance hídrico espacial mediante el uso de herramientas estadísticas, geoestadísticas y Sistemas de Información Geográfica. Finalmente, todas las capas de información generadas (84) han sido validadas y se ha comprobado que su creación admite un cierto grado de automatización que permitirá incorporarlas en análisis de Minería de Datos más amplios.

Palabras clave: modelos climáticos; sistemas de información geográfica; minería de datos; balance hídrico; Marina Baja.

Resum. Aplicació d'un model geogràfic amb informació climàtica per al càlcul del balanç hidric de la comarca de la Marina Baixa (Alacant)

Aquest treball analitza les noves tendències en la creació i gestió d'informació geogràfica, per a l'elaboració de models inductius basats exclusivament en bases de dades geogràfiques. Aquests tipus de models permeten integrar grans volums de dades de característiques hete- 
rogènies, la qual cosa suposa una gran complexitat tècnica i metodològica. Es proposa una metodologia que permet conèixer detalladament la distribució dels recursos hídrics naturals en un territori i derivar nombroses capes d'informació que puguin ser incorporades dins d'aquests models «àvids de dades» (data-hungry). La zona d'estudi escollida per aplicar aquesta metodologia és la comarca de la Marina Baixa (Alacant), per a la qual es presenta un càlcul del balanç hídric espacial mitjançant l'ús d'eines estadístiques, geoestadístiques i Sistemes d'Informació Geogràfica. Finalment, totes les capes d'informació generades (84) han estat validades i s'ha comprovat que la seva creació admet un cert grau d'automatització que permetrà incorporar-les dins d'anàlisis de Mineria de Dades més amplis.

Paraules clau: models climàtics; sistemes de informació geogràfica; mineria de dades; balanç hídric; Marina Baixa.

Résumé. Mise en cuvre d'un modèle géographique avec des informations sur le climat pour calculer l'équilibre de l'eau dans la région de Marina Baja (Alicante)

Cet article traite des nouvelles tendances dans la création et la gestion de l'information géographique pour le développement de modèles inductifs fondés uniquement sur des bases de données géographiques. Ces modèles permettent d'intégrer d'importants volumes de données aux caractéristiques hétérogènes, ce qui représente une grande complexité technique et méthodologique. L'article propose une méthodologie qui permet de connaître en détail la répartition des ressources hydriques naturelles d'un territoire, et de dériver de nombreux niveaux d'information qui peuvent être incorporés aux modèles "avides de données" (data-hungry). La zone d'étude choisie pour appliquer cette méthodologie est le quartier de la Marina Baja (Alicante), pour lequel une estimation du bilan hydrique spatial est présentée à l'aide d'outils statistiques, géostatistiques et SIG. Finalement, toutes les couches générées (84) ont été validées d'une part, puis on a vérifié que ce modèle prenait en charge un certain degré d'automatisation pour incorporer ces couches à une analyse "data-mining» de plus grande importance.

Mots-clés: modèles climatiques; systèmes d'information géographique; " data-mining "; bilan hydrique; Marina Baja.

Abstract. Application of a geographic model with climate information to calculate the water balance of the Marina Baja area of Alicante

This paper discusses new trends in the creation and management of geographic information for the development of inductive models based entirely on geodatabases. These models enable the integration of large volumes of data with heterogeneous characteristics, which is of an enormous technical and methodological complexity. We propose a methodology to determine the distribution of natural water resources in a study area and derive numerous geospatial layers that can be incorporated into these "data-hungry" models. The Marina Baja is the study area chosen to apply this methodology. An estimation of the spatial water balance is presented using statistical tools, geostatistics and geographic information systems. Finally, the layers generated (84) have been validated, thus demonstrating that the creation of such layers allows for a convenient degree of automation that permits them to be incorporated into broader data mining studies.

Keywords: climate models; geographic information systems; data mining; water balance; Marina Baja. 


\section{Sumario}

$\begin{array}{ll}\text { Introducción } & \text { Discusión } \\ \text { Metodología } & \text { Referencias bibliográficas }\end{array}$

\section{Introducción}

\section{Tendencias en la creación y la gestión de la información}

En los últimos años, la cantidad de datos recogidos y almacenados por los nuevos dispositivos electrónicos de almacenamiento ha aumentado enormemente; por ejemplo, los satélites de observación de la Tierra han obtenido gran cantidad de imágenes, los escáneres de código de barras han recogido grandes cantidades de datos sobre clientes y las aplicaciones móviles han facilitado la toma de datos durante el trabajo de campo (Camp \& Wheaton, 2014). Otras fuentes de datos pueden ser la propia Internet. Actualmente, la Web ofrece más de seis mil millones de páginas web y estas contienen información sobre casi cualquier tema imaginable (Google, 2011). Todo ello está generando cantidades ingentes de datos cada día. En cuanto a la información geográfica, las nuevas técnicas de generación de Información Geográfica Voluntaria (VGI) y la mayor disponibilidad de las Infraestructuras de Datos Espaciales (IDE) constituyen repositorios de datos de gran interés (Elwood et al., 2014).

Todas estas colecciones de datos son casi imposibles de analizar de forma manual. Los métodos para el análisis automático de datos, basados en la estadística clásica y en el aprendizaje automático (machine learning), se enfrentan a problemas en el tratamiento de grandes y complejos repositorios de datos. No obstante, esto no tiene por qué ser negativo, ya que incluso los modelos geográficos más sencillos combinan numerosas variables, por lo que pueden ser considerados como data hungry (Parker et al., 2008). El área del Descubrimiento del Conocimiento en Bases de Datos (KDD) proporciona técnicas que extraen patrones interesantes de los datos y todo ello en un tiempo razonable. El KDD se sitúa en un cruce entre el aprendizaje automático, la estadística y los sistemas de base de datos (Maimon y Rokach, 2010). Esta metodología permite analizar el gran volumen de datos geográficos que se puede obtener para una región y formular modelos sobre el territorio de un modo ágil. En Xu et al. (1998) se define KDD como «el proceso no trivial de identificación de patrones válidos, nuevos, potencialmente útiles y comprensibles, dentro de los datos».

Resulta necesario señalar que, tener un aceptable grado de automatización en la gestión y la captura de los datos es requisito indispensable para aplicar el KDD, ya que si no se dispone de la infraestructura necesaria para capturar y almacenar convenientemente la información, difícilmente se podrá obtener nada de ella sin un esfuerzo desproporcionado. Esto implica que antes de poder adquirir nuevos conocimientos con Minería de Datos, se debe trabajar en mejorar los sistemas de automatización y control de los datos, de modo que se pueda construir una base de datos coherente, exhaustiva y de buena 
calidad. Las herramientas de Minería de Datos serán útiles en este momento, cuando ya se dispone de un volumen de información importante y de buena calidad (Maimon y Rokach, 2010; Gibert y Sànchez-Marré, 2011). Así, en este trabajo se ha prestado especial atención a las fases de generación y de gestión de la información climática, con lo que se pretende facilitar las tareas de preprocesado en futuros proyectos.

El objetivo principal de este trabajo es comprobar si en la actualidad ya se dispone de los datos y los servicios de descarga de datos climáticos necesarios para generar modelos territoriales con la metodología KDD. La respuesta a esta cuestión puede ser intuida con bastante facilidad. A pesar de que sí que existe abundante información pública, el acceso y la gestión de dicha información deberán mejorar sustancialmente si se pretende generar modelos territoriales inductivos basados exclusivamente en bases de datos geográficas.

\section{Acceso a registros climáticos}

Una IDE (Infraestructura de Datos Espaciales) se puede definir como el conjunto de tecnologías, políticas, normas y recursos humanos necesarios para adquirir, procesar, almacenar, distribuir y mejorar el acceso a la información geográfica. Esta definición fue la propuesta para la creación de la National Spatial Data Infrastructure de los Estados Unidos de Norte América (NSDI) ${ }^{1}$. Del mismo modo, durante los últimos años, muchos países europeos han estado desarrollando sus propias IDE². Desde 2007, la normativa INSPIRE constituye un marco jurídico para la creación de una IDE europea, basada en las IDE creadas a nivel nacional, por lo tanto existe una voluntad política que promueve el libre acceso a los datos que permitirían la aplicación de una metodología KDD y poder así realizar modelos geográficos para cualquier área de la Unión Europea.

De acuerdo con la Directiva INSPIRE, los datos meteorológicos deben proporcionar información suficiente a los usuarios para evaluar, como mínimo, la precipitación, la temperatura, la evapotranspiración y el viento de cualquier punto de la UE. Además, otro tipo de datos más concretos también deberían estar disponibles. Sin embargo, ni la Directiva INSPIRE ni ninguno de los documentos posteriores especifican los detalles de todos los datos climáticos que se deberían incluir. No hay aún consenso en cuestiones como la lista de parámetros, la resolución espacial y temporal de los datos, o los protocolos a seguir ${ }^{3}$. No obstante, INSPIRE también indica que debe tenerse en cuenta que el volumen de datos creados, intercambiados y archivados por los centros meteorológicos

1. Executive Order 12906 of April 11, 1994 by President of the United States Coordinating Geographic Data Acquisition and Access: The National Spatial Data Infrastructure.

2. Directive 2007/2/EC of the European Parliament and of the Council of 14 March 2007 establishing an Infrastructure for Spatial Information in the European Community (INSPIRE). Ver <http://inspire.jrc.ec.europa.eu/>.

3. INSPIRE Data Specification for the spatial data theme Atmospheric Conditions and Meteorological Geographical Features. Versión: 3.0 rc2. 
nacionales en la UE es enorme. Estos recursos no se comparten habitualmente a través de Internet, sino a través de protocolos de descarga masiva de datos. Por este motivo los datos deben ser tratados previamente y resumidos si se quiere consultar la información a través de servicios web más habituales.

La Agencia Estatal de Meteorología (AEMET) sintonizaba con esta voluntad de apertura de los datos, pero como se explicaba en un artículo de prensa del 30 de octubre de 2012, se ha producido un retroceso en esta tendencia. Con anterioridad a dicha fecha, estaba disponible la descarga gratuita de datos en bruto, pero esta ha vuelto a ser reemplazada por peticiones administrativas de "pago por dato». Destacados investigadores como Javier Martín-Vide, Catedrático de Geografía Física de la Universidad de Barcelona, o Manuel de Castro, Catedrático de Física de la Tierra de la Universidad de Castilla-La Mancha, coinciden en que se trata de un retroceso ${ }^{4}$. A pesar de todo ello, es necesario continuar perseverando en la definición de metodologías y servicios interoperables que agilicen el tratamiento previo de los datos climáticos.

\section{Modelización del clima en la Marina Baja}

Como se ha mencionado previamente, se quiere evaluar la disponibilidad de los datos climáticos necesarios para generar modelos territoriales con la metodología KDD. Para ello, se ha escogido como zona de estudio la comarca de la Marina Baja (Alicante). El paisaje de esta comarca ha sido muy estudiado con anterioridad y existen abundantes orígenes de datos geográficos de utilidad para estudios como el propuesto aquí.

La Marina Baja cuenta con una superficie de 579,63 km²; el 41,4\% de los cuales corresponden a los siete municipios litorales (Alfaz del Pi, Altea, Benidorm, Finestrat, La Nucía, Polop y Villajoyosa). Sin embargo, las trascendencias demográfica y económica de estos municipios exceden ampliamente -más del 95\% - a las cifras totales de los doce municipios comarcanos restantes.

La demográfica no es la única disimetría de la comarca, las hay también de orden físico en cuanto a relieve y clima. La precipitación anual media se reduce, prácticamente, a la mitad de Denia $(674 \mathrm{~mm})$ a Benidorm $(335 \mathrm{~mm})$. La aridez, ocasionada por precipitaciones escasas, irregulares e intensas, con elevada evapotranspiración potencial, es un rasgo definitorio de la Marina Baja. Es de notar que la comarca limita, al norte, con la de la Marina Alta, donde radican los observatorios (Tormos, $918 \mathrm{~mm}$; Pego, 816) más lluviosos de las tierras alicantinas. Y cabe destacar que las Masas de Agua de la Marina Baja, merced a la escorrentía subterránea, que desborda los límites de las cuencas epigeas, se nutren, parcialmente, de dicho incremento pluviométrico, como evidencian las de Serrella-Aixorta-Algar, que incluye los acuíferos de Beniardá y Algar, y Sierra Aitana, con los de Polop y Aitana Sur. Precisamente por esta gran

4. «Meteorología cobrará por millones de datos hasta ahora públicos». Diario El País [30 de octubre de 2012]: <http://sociedad.elpais.com/sociedad/2012/10/29/actualidad/1351532849_517117.html>. 


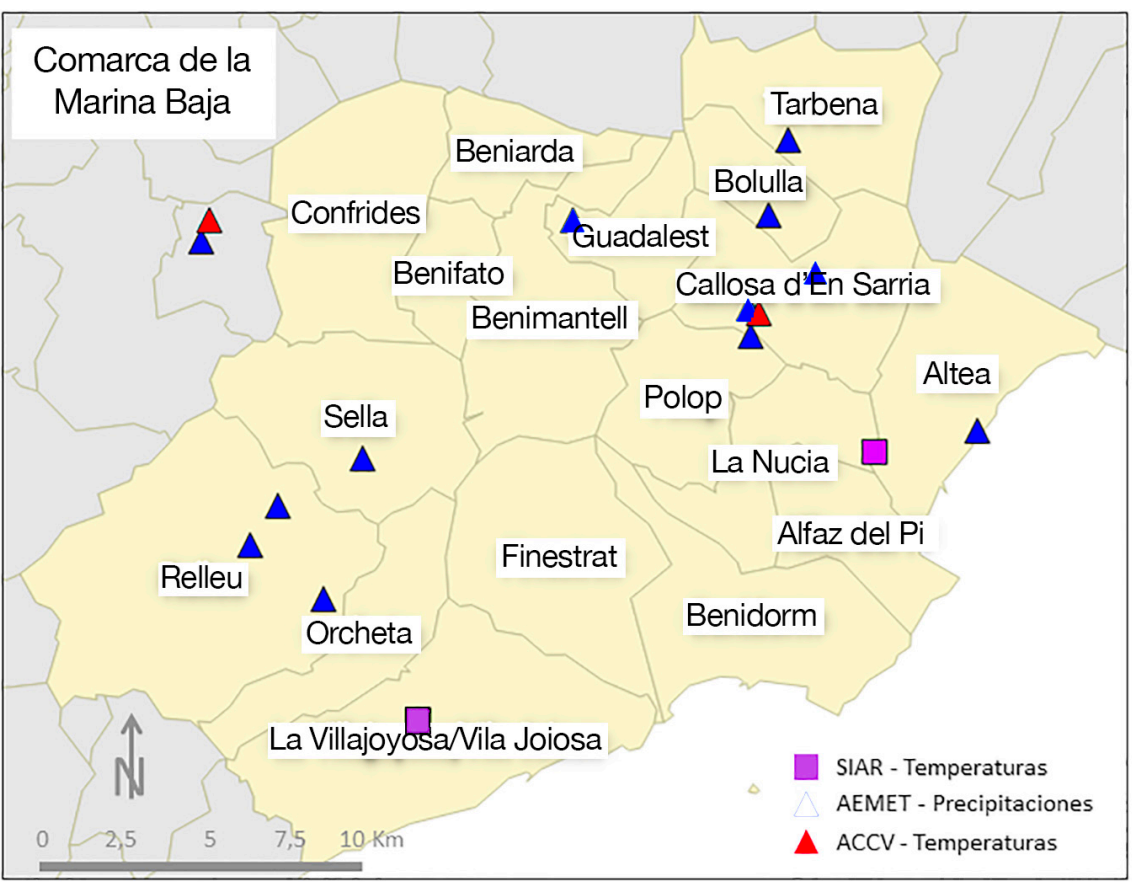

Figura 1. Localización de la Marina Baja, sus municipios y las estaciones meteorológicas empleadas.

Fuente: AEMET.

complejidad de la hidrología de la comarca es por lo que la Marina Baja ha sido ampliamente estudiada a través de observaciones y modelos hidrológicos.

Distintos modelos hidrológicos han sido anteriormente utilizados para estudiar la gestión de los recursos hídricos de la comarca, asumiendo distintos valores para la oferta y la demanda de agua (Ruíz, 1998; Andreu et al., 1996). Por otro lado, Sánchez et al. (2004) aportan los resultados de un balance hídrico bastante detallado, en el que se calcula la evapotranspiración para los distintos tipos de usos del suelo, matizando certeramente las pérdidas de agua en el sistema. A pesar de la utilidad que puedan tener estos métodos, los resultados no dan una idea de la distribución espacial de las necesidades, o reservas hídricas. En cambio, existen otros ejemplos muy interesantes sobre el cálculo del balance hídrico de otras regiones mediante el uso de SIG (Reed et al., 1997; Dripps y Bradbury, 2007). Finalmente, las técnicas más recientes para el cálculo del balance hídrico se basan en el empleo de la teledetección de imágenes de satélite. Un ejemplo de aplicación de las técnicas más avanzadas a nivel continental es el llevado a cabo por Liu et al. (2006) para la región de Sudamérica, además ya se apuntan futuras líneas de investigación y mejoras proyectadas en los sensores 
que emplean. El estudio a partir de estas fuentes resulta bastante costoso debido a la exclusividad de los sensores empleados, pero se presenta como una vía de estudio idónea y que también se podría integrar en estudios KDD. A pesar de existir métodos suficientemente contrastados, algunos de estos no son tan ágiles y económicos como precisaría una metodología KDD. En caso de querer realizar una caracterización mensual del clima y el balance hídrico espacial mediante teledetección se necesitan muchas imágenes de satélite por cada mes, y aun siendo esto posible en ciertas plataformas, sería igualmente necesaria una cierta serie de años de observación, así como el tratamiento de toda la información.

Finalmente, en esta investigación se opta por una metodología más ágil y fácil de automatizar. El cálculo del balance hídrico espacial de los suelos agrícolas se realiza mediante el uso de herramientas estadísticas, geoestadísticas y SIG. A partir de esta metodología, entre otras aplicaciones posibles, se puede obtener una rápida aproximación a los caudales esperados en distintas partes del territorio, o también el grado en que la agricultura de la comarca se ve condicionada por las disponibilidades hídricas y por el clima en general. Estas capas de información, así como las capas intermedias generadas (precipitaciones, temperaturas, radiación solar, entre otras), han sido esenciales en la generación de modelos KDD de la Marina Baja, donde se ha logrado describir el abandono agrícola de la comarca partiendo de esta metodología de carácter inductivo y semiautomático (Zaragozí et al., 2012).

\section{Metodología}

En el caso de la Marina Baja, el número de observatorios meteorológicos con series aptas para el estudio de las distintas variables climáticas es más bien insuficiente para llevar a cabo una modelización cartográfica a escala de detalle. Así pues, se considera imprescindible elaborar modelos que aporten nueva información, con una exactitud tal que permitan estudiar las relaciones del clima con el paisaje.

Las variables necesarias para estudiar el balance hídrico de esta región son: la radiación solar, temperaturas (máximas, medias y mínimas) y precipitaciones, a partir de las cuales se derivarán otras como la evapotranspiración potencial y se calculará una ficha hídrica espacial. Los tipos de modelos que se emplean varían según la variable analizada, así que mientras que la radiación se aproxima mediante un modelo físico (Wilson y Gallant, 2001), las precipitaciones y temperaturas se estudian con el uso de un modelo geoestadístico (Ninyerola et al., 2000). Todos los modelos se han calculado a una escala provincial, con una resolución que facilita la agilidad de todos los cálculos necesarios (píxeles de $100 \times 100 \mathrm{~m}$ ). El software utilizado es SAGA GIS, pero esta metodología podría reproducirse con cualquier otro software GIS con capacidades raster. En la Figura 2 se resume el proceso completo de modelización que se desarrolla a continuación.

\section{Temperatura}

Para el estudio de las temperaturas se cuenta con abundante información de distintas procedencias. Se ha contado con datos diarios de temperatura máxi- 


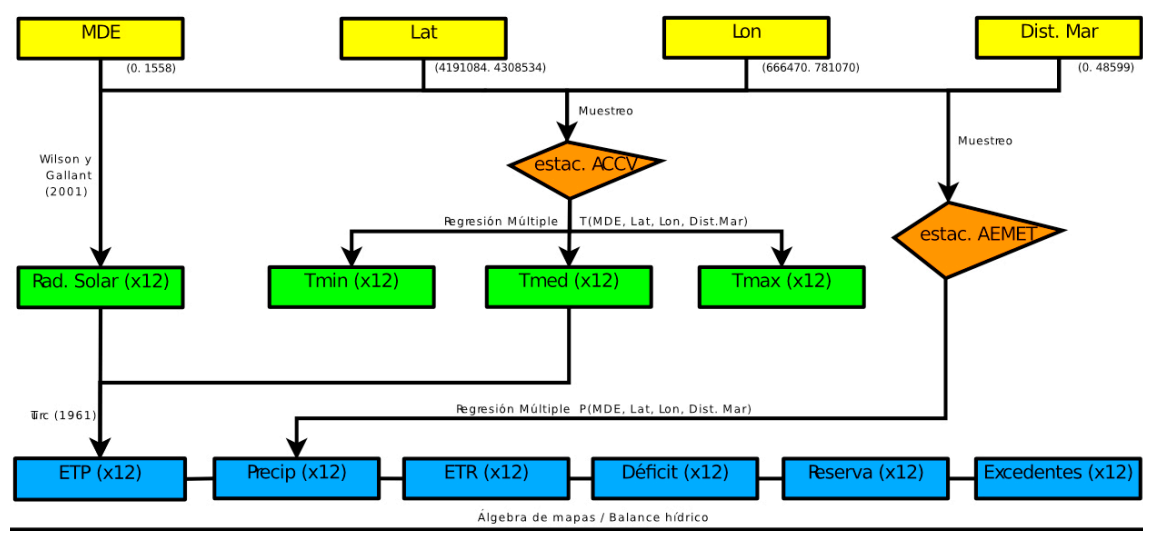

Figura 2. Modelo geográfico para aplicar la ficha del balance hídrico espacial.

Fuente: elaboración propia.

ma y mínima cedidos por AEMET. Sin embargo, en Pérez Cueva (1994) se dispone de unas series de registros mensuales ya depuradas y completadas, que abarcan desde 1961 a 1990, por lo cual se estima que aun no siendo una serie actualizada, sí que puede ser representativa de las condiciones medias, y de la distribución espacial de las temperaturas de la comarca. Además, se cuenta con observatorios bien distribuidos a lo largo y ancho de la provincia de Alicante, lo que permite el estudio de las temperaturas con la metodología propuesta. Disponer de una base de datos similar en otras regiones sería muy útil para lograr aplicar una metodología KDD geográfica de un modo estándar.

Los datos agregados de las estaciones meteorológicas (temperaturas máximas, mínimas y medias mensuales) de la provincia de Alicante se han interpolado por el método geoestadístico de regresión múltiple con interpolación de residuales (Ninyerola et al., 2000). La interpolación de los residuos se ha obtenido mediante el Inverso de la Distancia Ponderada (IDW), que es un método sencillo de aplicar utilizado también en Ninyerola et al. (2000). Las capas anuales se calculan mediante álgebra de mapas a partir del promedio (o sumatorio en el caso de las precipitaciones) de las capas mensuales. La automatización parcial y la supervisión de este proceso podrían agilizar la integración de variables climáticas en una metodología KDD como la que aquí se propone. A continuación, en las tablas 1, 2 y 3 se resumen algunas estadísticas de los resultados obtenidos en el análisis de las temperaturas, y se comentan algunas peculiaridades y observaciones de dichos análisis.

Evidentemente, $\mathrm{R}^{2} \mathrm{c}$ (bondad de ajuste corregida) es siempre mayor que $\mathrm{R}^{2} \mathrm{nc}$ (bondad de ajuste no corregida) debido a que los datos reales incorporados al análisis no pueden sino mejorar el modelo. Los valores de estos coeficientes de determinación han resultado bastante altos en general, solamente han sido más bajos para los meses de verano. Esta variación parece relacionada 
Tabla 1. Estadísticas representativas de la modelización de las temperaturas máximas

\begin{tabular}{lrrccrccccc}
\hline Mes & $\mathrm{R}^{2} \mathrm{nc}$ & $\mathrm{R}^{2} \mathrm{C}$ & RMSE $\left({ }^{\circ} \mathrm{C}\right)$ & Variables & Mín. & Máx. & Rango & Media & Desv. Std. & Obs. \\
\hline Ene & 0,71 & 0,78 & 1,15 & $\mathrm{z}$ & 3,34 & 17,60 & 14,27 & 13,33 & 2,67 & $\mathrm{R}^{2} \mathrm{C} \rightarrow 0,94$ \\
Feb & 0,84 & 0,86 & 1,06 & $\mathrm{x}, \mathrm{z}$ & 3,31 & 20,03 & 16,72 & 15,35 & 3,24 & $\mathrm{R}^{2} \mathrm{c} \rightarrow 0,89$ \\
Mar & 0,76 & 0,72 & 1,10 & $\mathrm{x}, \mathrm{z}$ & 4,91 & 21,38 & 16,47 & 16,67 & 2,89 & $\mathrm{R}^{2} \mathrm{C} \rightarrow 0,79$ \\
Abr & 0,73 & 0,93 & 1,18 & $\mathrm{y}, \mathrm{cont}$ & 8,52 & 24,00 & 15,49 & 18,76 & 2,61 & \\
May & - & 0,79 & 1,00 & $\mathrm{x}, \mathrm{z}$ & 13,95 & 27,01 & 13,07 & 22,57 & 2,26 & $\mathrm{R}^{2} \mathrm{C} \rightarrow 0,76$ \\
Jun & - & $<0,58$ & 2,02 & $\mathrm{Y}$ & 23,00 & 32,00 & 9,00 & 26,93 & 1,65 & \\
Jul & - & $<0,57$ & 1,83 & $\mathrm{X}$ & 27,00 & 35,00 & 8,00 & 30,96 & 1,40 & \\
Ago & - & 0,62 & 1,13 & $\mathrm{x}, \mathrm{z}$ & 25,33 & 34,00 & 8,68 & 30,41 & 1,69 & \\
Sep & - & $<0,53$ & 1,63 & $\mathrm{y}$ & 24,00 & 32,00 & 8,01 & 27,74 & 1,56 & \\
Oct & 0,63 & 0,78 & 1,29 & $\mathrm{x}, \mathrm{z}$ & 11,52 & 27,00 & 15,47 & 22,16 & 2,51 & $\mathrm{R}^{2} \mathrm{C} \rightarrow 0,85$ \\
Nov & 0,68 & 0,67 & 1,27 & $\mathrm{x}, \mathrm{z}$ & 5,17 & 21,03 & 15,86 & 16,82 & 2,64 & $\mathrm{R}^{2} \mathrm{c} \rightarrow 0,92$ \\
Dic & 0,66 & 0,64 & 1,27 & $\mathrm{x}, \mathrm{y}$ & 2,17 & 18,00 & 15,83 & 13,75 & 2,68 & $\mathrm{R}^{2} \mathrm{C} \rightarrow 0,92$ \\
\hline
\end{tabular}

Nota: Variables $\rightarrow X=$ longitud, $Y=$ latitud, $Z=$ altitud, cont = continentalidad.

Observaciones $\rightarrow$ se refiere a la mejora del $R^{2} \mathrm{C}$ al eliminar un solo observatorio de su cálculo.

Fuente: elaboración propia.

con el menor rango de temperaturas a lo largo de la zona de estudio, es decir, hay una mayor homogeneidad, y por este motivo las diferencias son más difíciles de explicar. Por otro lado, en el caso de las temperaturas máximas, se ha observado que hay observatorios con personalidad propia que, seguramente por unas condiciones muy locales o incluso microclimáticas no se adaptan al modelo establecido para ciertos meses. Considerando la puntualidad y el distanciamiento espacial de estas diferencias, se considera que el modelo para la Marina Baja es incluso mejor de lo estimado. En caso de realizar un estudio más detallado del clima de la provincia se podrían analizar con más detenimiento estas observaciones, pero en un estudio KDD donde lo prioritario es la agilidad estas consideraciones serían más que suficientes.

Se ha calculado además otro estadístico para valorar la exactitud de los modelos mensuales que se conoce como la raíz cuadrada del error medio cuadrático (root mean square error, RMSE). El cálculo de la raíz cuadrada produce un estadístico de ajuste con la misma métrica que la serie de los errores y la serie observada, lo que significa que tendremos una buena aproximación del error en ${ }^{\circ} \mathrm{C}$ que se puede dar en cada modelo. Esto resulta muy útil ya que permite modificar el modelo del modo más optimista o pesimista posible, creando intervalos de confianza alrededor del modelo obtenido. Cabe recordar, que en el modelo final de cada mes el RMSE será seguramente menor que el aquí señalado. De todos modos, los errores calculados oscilan como media entre $\pm 1^{\circ} \mathrm{C}$, lo que da una idea de la buena exactitud de los modelos. En el peor de los casos (temperaturas máximas de junio y julio), se pueden alcanzar errores de $\pm 1,8^{\circ} \mathrm{C}$ y $\pm 2^{\circ} \mathrm{C}$. Esta dificultad de predicción hace pensar que las variables que modifican esta normal en el verano no han sido contempladas, y posiblemente tengan un condicionamiento muy local (litología, tipos de suelo, usos de suelo, vientos, entre otros). 
Tabla 2. Estadísticos representativos de la modelización de las temperaturas medias

\begin{tabular}{|c|c|c|c|c|c|c|c|c|c|c|}
\hline Mes & $R^{2} n c$ & $\mathrm{R}^{2} \mathrm{C}$ & RMSE $\left({ }^{\circ} \mathrm{C}\right)$ & Variables & Min. & Máx. & Rango & Media & Desv. Std. & Obs. \\
\hline Ene & 0,89 & 0,90 & 0,80 & $z$ & $-1,71$ & 13,12 & 14,83 & 8,63 & 2,67 & \\
\hline Feb & 0,86 & 0,87 & 1,04 & z & 0,19 & 14,09 & 13,90 & 9,66 & 2,55 & \\
\hline Mar & 0,92 & 0,93 & 1,03 & z & 2,66 & 16,04 & 13,38 & 11,15 & 2,42 & \\
\hline Abr & 0,86 & 0,87 & 1,09 & z & 5,75 & 18,03 & 12,28 & 13,34 & 2,30 & \\
\hline May & 0,69 & 0,81 & 1,24 & z & 10,42 & 22,00 & 11,58 & 16,76 & 2,01 & \\
\hline Jun & 0,57 & 0,73 & 1,33 & $z$ & 14,00 & 26,00 & 12,00 & 20,67 & 1,87 & $\mathrm{R}^{2} \mathrm{C} \rightarrow 0,9$ \\
\hline Jul & 0,52 & 0,69 & 1,12 & z & 19,14 & 29,00 & 9,86 & 24,33 & 1,41 & $\mathrm{R}^{2} \mathrm{C} \rightarrow 0,9$ \\
\hline Ago & 0,70 & 0,84 & 1,08 & $z$ & 18,33 & 29,00 & 10,67 & 24,13 & 1,77 & \\
\hline Sep & 0,87 & 0,87 & 1,02 & z & 14,18 & 26,01 & 11,83 & 21,23 & 2,08 & \\
\hline 0ct & 0,92 & 0,93 & 0,89 & z & 8,15 & 21,07 & 12,92 & 16,73 & 2,36 & \\
\hline Nov & 0,90 & 0,93 & 0,87 & z & 2,44 & 16,11 & 13,67 & 12,07 & 2,52 & \\
\hline Dic & 0,91 & 0,96 & 0,79 & z & $-1,44$ & 13,13 & 14,57 & 9,03 & 2,67 & \\
\hline
\end{tabular}

Nota: Variables $\rightarrow \mathrm{x}=$ longitud, $\mathrm{y}=$ latitud, $\mathrm{z}=$ altitud, cont $=$ continentalidad.

Observaciones $\rightarrow$ se refiere a la mejora del $R^{2} \mathrm{C}$ al eliminar un solo observatorio de su cálculo.

Fuente: elaboración propia.

En cada tabla de estadísticos se ha hecho una relación de las variables que han sido significativas en su modelo correspondiente. Se pueden extraer algunas conclusiones de la importancia que tiene cada variable para el clima de la zona de estudio. Se aprecian algunos hechos relevantes:

- La altitud es siempre relevante en el estudio de las temperaturas, siendo indispensable por ejemplo en la estimación de las temperaturas medias.

- La variable que más determina las temperaturas mínimas es la distancia al mar (cont), incluso en mayor grado que la altitud. Este hecho se atribuye al carácter regulador del mar Mediterráneo. Resulta pues interesante estudiar con más detenimiento el efecto de la continentalidad para el estudio de esta variable.

- Las temperaturas medias se correlacionan bien solamente con la altitud, hecho a tener en cuenta en próximos estudios de la zona, con miras a ahorrar tiempo de trabajo.

- En el caso de las temperaturas máximas y mínimas, los modelos no mejoran en la misma proporción que como sucede con las medias, lo que hace pensar en la posibilidad de buscar nuevas variables explicativas que se puedan representar espacialmente. Se ha ensayado incluir variables como la radiación solar o la insolación, pero se han desestimado ya que en ambos casos existía una elevada colinealidad ${ }^{5}$ respecto a las demás variables, pues su introducción o no en los modelos no modificaba notoriamente los coefi-

5. La colinealidad se da al introducir en un modelo de regresión dos variables independientes que se correlacionan muy bien entre sí, en este caso ambas pueden aparecer como poco significativas, pero en caso de introducir solo una de ellas sí parecería significativa. 
Tabla 3. Estadísticas representativas de la modelización de las temperaturas mínimas

\begin{tabular}{lccccrrrrrr}
\hline Mes & R $^{2} \mathrm{nc}$ & $\mathrm{R}^{2} \mathrm{C}$ & RMSE $\left({ }^{\circ} \mathrm{C}\right)$ & Variables & Mín. & Máx. & Rango & Media & Desv. Std. & Obs. \\
\hline Ene & 0,67 & 0,80 & 1,59 & cont & $-1,02$ & 9,01 & 10,04 & 4,51 & 2,04 & \\
Feb & 0,62 & 0,81 & 1,46 & cont & $-0,02$ & 9,02 & 9,04 & 5,26 & 1,92 & \\
Mar & 0,56 & 0,71 & 1,62 & cont & 0,98 & 11,02 & 10,03 & 6,30 & 1,99 & \\
Abr & 0,84 & 0,86 & 1,22 & z & $-0,40$ & 13,00 & 13,41 & 7,78 & 2,38 & \\
May & 0,46 & 0,64 & 1,58 & cont & 4,99 & 16,01 & 11,02 & 11,49 & 1,72 & R$^{2} \mathrm{C} \rightarrow 0,8$ \\
Jun & - & 0,87 & 1,38 & z & 5,82 & 20,00 & 14,18 & 14,53 & 2,40 & \\
Jul & - & 0,90 & 1,49 & z & 9,49 & 23,00 & 13,51 & 17,64 & 2,21 & \\
Ago & 0,56 & 0,58 & 1,63 & cont & 12,98 & 23,02 & 10,04 & 18,49 & 1,95 & \\
Sep & 0,62 & 0,69 & 1,71 & cont & 9,98 & 21,01 & 11,03 & 15,93 & 2,03 & \\
Oct & 0,66 & 0,74 & 1,47 & cont & 5,98 & 17,03 & 11,05 & 11,99 & 2,21 & \\
Nov & 0,83 & 0,87 & 1,28 & z, cont & 0,49 & 12,05 & 11,56 & 7,43 & 2,43 & \\
Dic & 0,79 & 0,96 & 1,27 & z, cont & $-3,07$ & 9,05 & 12,13 & 4,45 & 2,49 & \\
\hline
\end{tabular}

Nota: Variables $\rightarrow \mathrm{x}=$ longitud, $\mathrm{y}=$ latitud, $\mathrm{z}=$ altitud, cont $=$ continentalidad.

Observaciones $\rightarrow$ se refiere a la mejora del $R^{2} \mathrm{C}$ al eliminar un solo observatorio de su cálculo.

Fuente: elaboración propia.

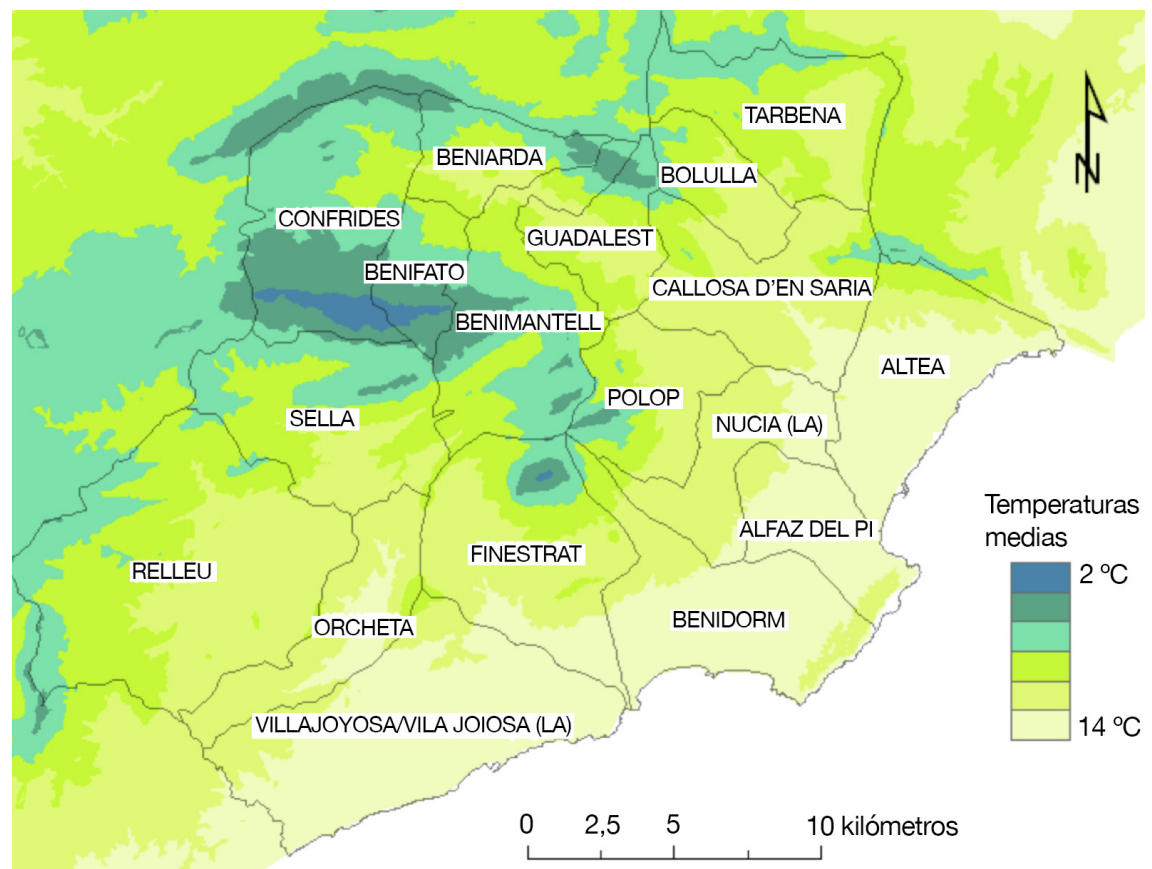

Figura 3. Estimación de las temperaturas medias de marzo.

Fuente: elaboración propia. 
cientes de regresión de las demás variables. En futuros estudios se planteará la incorporación de variables descriptoras de la complejidad del relieve como la rugosidad.

\section{Precipitaciones}

Para el estudio de las precipitaciones se ha contado con mayor cantidad de observatorios. En este caso, los datos procedentes de las series diarias completas de toda la provincia de Alicante, proporcionadas por la AEMET. Al no contar, en principio, con unas series de datos homogeneizadas, se ha seguido con lo recomendado por Ninyerola et al. (2000), y se ha tratado de encontrar una solución de compromiso entre la resolución espacial y la temporal. Así pues, se han seleccionado todos los observatorios con series completas de veinte años o más, a pesar de que estas series correspondieran a períodos distintos, tratando siempre de que dichas series estuviesen lo más próximas a la última fecha disponible (se ha contado con la totalidad de los registros hasta diciembre de 2005). Merece la pena encarecer que para las precipitaciones se ha contado con un mayor número de observatorios, lo cual no solamente mejora el análisis sino que también aumenta la validez de las pruebas de control $\left(R^{2} n c\right.$ y $\left.R^{2} c\right)$.

$\mathrm{Al}$ analizar los valores del coeficiente de determinación en el caso de las precipitaciones se hace patente que su estimación es mucho más compleja. El coeficiente nunca llega a un $90 \%$ de explicación de la varianza. La interpretación del RMSE (en este caso se habla de $1 / \mathrm{m}^{2} \mathrm{o} \mathrm{mm}$ de precipitación) arroja valores muy relacionados con el rango de precipitaciones de toda la provincia. Por otro lado, son datos muy interesantes los referentes a los máximos y mínimos, siendo evidentes los grandes contrastes a lo largo de la provincia.

Las variables representativas de los distintos modelos reflejan algunas anécdotas, como por ejemplo, que la altitud sea un factor tan poco significativo (solamente aparece en un $8 \%$ de los modelos mensuales de precipitación). Entre las variables consideradas en los modelos de precipitación, destacan la distancia al mar (cont), y la longitud (x) muy en primer lugar, cuando era de esperar que la latitud fuese de entre las más significativas, de acuerdo al conocimiento que se tiene sobre la distribución de las precipitaciones en la provincia de Alicante. Este hecho no tiene por qué ser erróneo, pues atendiendo a la forma de la provincia se entiende que las precipitaciones en general son mayores en el NE de la provincia y, debido a una coincidencia, la longitud es mayor en aquellas zonas que se saben más lluviosas en la provincia. También se da en menor medida la anterior coincidencia pues los observatorios más lluviosos se encuentran bastante cerca del mar. Además, la latitud ha quedado excluida en muchos casos por la colinealidad respecto a la unión de las otras dos variables.

\section{Radiación solar}

Radiación solar e insolación son, en varios sentidos, variables muy importantes en los estudios agroclimatológicos. Por un lado, como condicionantes precisos 
Tabla 4. Estadísticas representativas de la modelización de las precipitaciones medias

\begin{tabular}{lrrrcrrrrr}
\hline Mes & Rnc & Rc & RMSE $\left(1 / \mathrm{m}^{2}\right)$ & Variables & Mín. & Máx. & Rango & Media & Desv. Std. \\
\hline Ene & 0,59 & 0,86 & 15,66 & x, y, cont & 13,09 & 100,46 & 87,36 & 35,28 & 19,80 \\
Feb & 0,72 & 0,75 & 11,12 & x, cont & 16,85 & 83,15 & 66,29 & 33,01 & 15,75 \\
Mar & 0,54 & 0,83 & 11,45 & y & 15,84 & 80,88 & 65,04 & 33,31 & 14,19 \\
Abr & 0,62 & 0,75 & 9,36 & x, z, cont & 10,88 & 86,60 & 75,72 & 37,65 & 12,69 \\
May & 0,61 & 0,73 & 8,32 & x, cont & 15,91 & 79,07 & 63,15 & 38,25 & 12,97 \\
Jun & 0,65 & - & 4,72 & x, cont & 9,79 & 44,62 & 34,83 & 24,27 & 6,74 \\
Jul & 0,59 & 0,65 & 1,81 & x, y & 2,09 & 12,83 & 10,74 & 5,99 & 2,24 \\
Ago & 0,61 & 0,75 & 3,82 & y, z & 0,14 & 30,99 & 30,85 & 11,08 & 5,59 \\
Sep & 0,69 & - & 11,51 & x, cont & 21,99 & 87,17 & 65,18 & 39,99 & 12,94 \\
Oct & 0,68 & - & 17,69 & x, cont & 27,50 & 149,66 & 122,15 & 58,93 & 24,20 \\
Nov & 0,67 & 0,81 & 14,50 & x, cont & 22,20 & 132,48 & 110,29 & 46,96 & 22,76 \\
Dic & 0,70 & 0,82 & 13,99 & x, cont & 19,79 & 110,89 & 91,10 & 42,42 & 22,11 \\
\hline
\end{tabular}

Nota: Variables $\rightarrow \mathrm{x}=$ longitud, $\mathrm{y}=$ latitud, $\mathrm{z}=$ altitud, cont $=$ continentalidad.

Fuente: elaboración propia.

para la vida, sobre todo de las plantas, y por otro lado son unas variables muy necesarias para el cálculo de otros fenómenos como la evapotranspiración o distintos índices útiles para valorar la adecuación de un territorio para determinadas especies. Se incluye la insolación en este apartado debido a que su cálculo es necesario para el de la radiación solar.

Se ha mencionado anteriormente que estas normales climáticas se pueden calcular mediante la aplicación de fórmulas físicas, y esta es la opción que se ha tomado al no disponer de suficientes observatorios con registro de estas variables. No obstante, para contrastar los resultados del modelo, sí que se han tenido en cuenta los datos disponibles en el Atlas Climático de la Comunidad Valenciana, y más recientemente en las estaciones del SIAR, próximas o del interior de la comarca.

El cálculo de la radiación se ha llevado a cabo reproduciendo la metodología propuesta por Wilson y Gallant (2001), por la que se calcula la radiación solar potencial en función de la latitud, pendientes, orientación, zonas de sombra, temperaturas y la fecha. Las condiciones atmosféricas consideradas son las medias, y solamente se tiene en cuenta la nubosidad como fracción entre el número de horas de sol medias mensuales, medidas con heliógrafo en las estaciones SIAR, y la insolación máxima posible.

La metodología de Wilson y Gallant sirve para calcular un balance de energía en la superficie, pero esto no es lo necesario en el caso aquí planteado, donde la radiación incidente es empleada solamente como parámetro necesario en el cálculo de la evapotranspiración potencial. El cálculo de la radiación solar se ha realizado a partir de un modelo digital de elevaciones generado mediante triangulación (Triangular Irregular Networks), que posteriormente se ha adaptado a la resolución de $100 \times 100 \mathrm{~m}$. La interpolación se ha realizado a partir de las isohipsas maestras de la serie cartográfica ICV10, que distribuye 
$\mathrm{cal} / \mathrm{cm}^{2} / \mathrm{dia}$

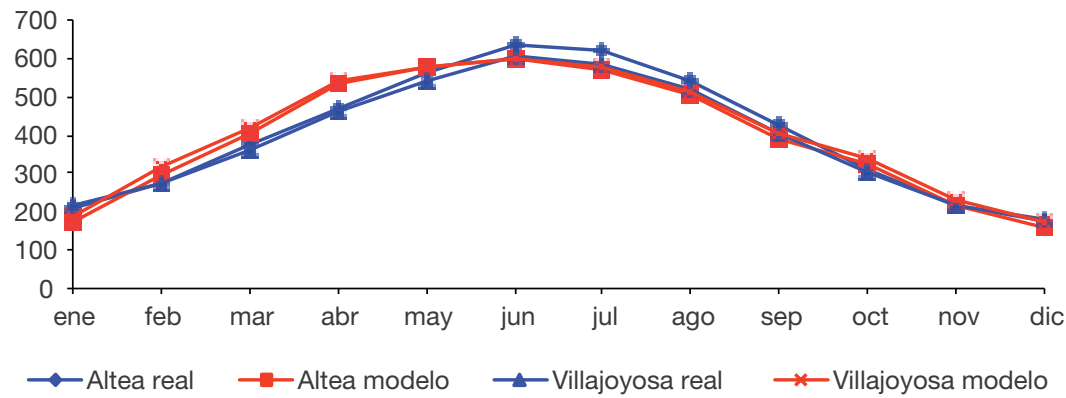

Figura 4. Comparación de la radiación solar incidente de los modelos frente a los datos reales.

Fuente: Instituto Valenciano de Investigaciones Agrarias y elaboración propia.

el Instituto Cartográfico Valenciano. El método de Wilson y Gallant (2001) para el cálculo de la radiación solar viene implementado en SAGA GIS (System for Automated Geoscientific Analyses). Esta metodología permite trabajar con un número mínimo de parámetros y variables de entrada, por lo que es ideal para su integración en un proceso KDD. Finalmente, se han obtenido doce capas raster con valores mensuales para cada una de las dos variables: insolación y radiación solar. La insolación se dispone en horas/mes, mientras que la radiación solar incidente se ha convertido a cal $/ \mathrm{cm}^{2} / \mathrm{día}$, pensando en su posterior aplicación para el cálculo de la evapotranspiración potencial.

A continuación, los resultados obtenidos pueden ser contrastados comparándolos con los observatorios de Altea y Villajoyosa (ver Figura 4). Los valores obtenidos son aceptables a pesar de apreciarse diferencias significativas en los meses de primavera. Estas diferencias pueden estar causadas por una infravaloración de la nubosidad u otros parámetros relacionados con esta época del año. Otras posibles fuentes de error son la resolución del modelo digital de elevaciones (MDE), o posibles efectos debidos al emplazamiento de las estaciones (proximidad a núcleos urbanos, efectos no considerados del relieve sobre la nubosidad, entre otros). Además, se hace notar que entre los valores de los modelos para las dos estaciones no hay prácticamente diferencias, mientras que entre los valores reales hay ciertas discrepancias, sobre todo, en los meses estivales. Evidentemente, lo ideal hubiese sido poder contrastar los modelos frente a los datos recogidos por un mayor número de observatorios, pero esto no es siempre posible.

En futuros estudios sobre estas variables sería aconsejable el uso de imágenes de satélite para la obtención de mapas medios de nubosidad, insolación efectiva y otras normales climáticas. No obstante, para las necesidades de este trabajo, los valores obtenidos son suficientemente buenos para estimar la variabilidad 


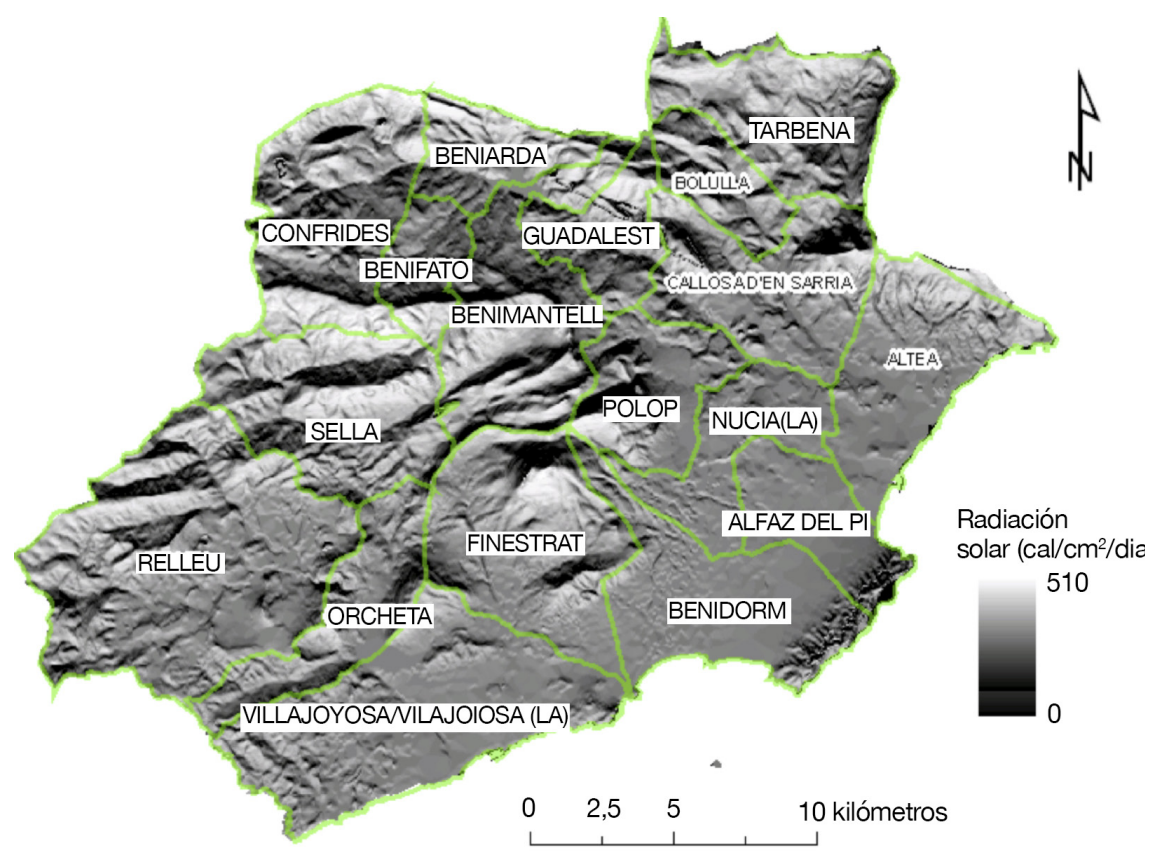

Figura 5. Estimación de la radiación solar potencial media del mes de marzo. Los colores más claros indican una radiación solar mayor.

Fuente: elaboración propia.

espacial de estos fenómenos en la comarca. Además, estos resultados son de mucha mayor relevancia que los calculados para un solo punto de la comarca.

Finalmente, cabe destacar la existencia de una red de cinco estaciones meteorológicas dependiente de la Cooperativa Agrícola de Callosa d'en Sarrià, la cual sería un buen complemento para cualquier estudio climático de Callosa d'en Sarrià o de sus alrededores. Se dispone de unos doce años de observaciones, lo cual es suficiente para el estudio de vientos, radiación y evapotranspiración. Sin embargo, la existencia de estos datos no se ha conocido con tiempo suficiente para incluirlos en el presente estudio. Este problema de acceso a los datos quedará solucionado cuando las IDE que se han comentado anteriormente alcancen cierto grado de madurez.

\section{Evapotranspiración potencial}

«Evapotranspiración potencial» es el concepto acuñado por Charles Thornthwaite (1948), como integrador de los conceptos de evaporación y transpiración, refiriéndose la evaporación a la evaporación directa desde un suelo desnudo hacia la atmósfera, mientras que la transpiración se refiere al agua evaporada desde las plantas para la realización de distintas necesidades fisiológicas. 
El concepto de evapotranspiración (ET) viene a reflejar la estrecha interrelación entre estas dos nociones, pues en la realidad son difícilmente separables. Su cálculo es esencial para el conocimiento de las necesidades hídricas de las plantas, la planificación de los cultivos, y en general, para cualquier estudio del medio ambiente o de la producción vegetal.

Se puede distinguir entre evapotranspiración potencial (ETP), evapotranspiración de referencia (ETo) y evapotranspiración real (ETr). El adjetivo potencial define una evapotranspiración dependiente únicamente de las condiciones meteorológicas, y por tanto no se tienen en cuenta condiciones propias del territorio estudiado, condiciones tales como la reserva de agua disponible en el suelo o las necesidades de las especies vegetales presentes en dicho territorio. En segundo lugar, la ETo es aplicada a un cultivo específico, estándar o de referencia, habitualmente gramíneas o alfalfa, de 8 a $15 \mathrm{~cm}$ de altura uniforme, de crecimiento activo, que cubre totalmente el suelo y que no se ve sometido a déficit hídrico. Por último, la ETr es más difícil de calcular que la ETP o ETo, ya que además de las condiciones climáticas, interviene la magnitud de las reservas de humedad del suelo y los requerimientos de los cultivos. Para ajustarla, primero se corrige la ETP o ETo con un factor Kc dependiente del nivel de humedad del suelo y de las características de cada cultivo.

Existen muchas fórmulas disponibles para el cálculo de la ETP. Son fórmulas que requieren distintos parámetros y que pueden ser más o menos acertadas según la región a la que se apliquen. Así pues, se debe seleccionar el método más preciso a partir de las variables espaciales estimadas (temperaturas máximas, mínimas y medias, precipitación y radiación solar).

En la Tabla 5 se recoge una relación de las fórmulas de mayor aplicación y los parámetros que requieren. Algunas de ellas quedan directamente excluidas por no poderlas aplicar espacialmente con los datos disponibles. Por ejemplo, los métodos Penman suelen requerir una calibración local de las variables de viento para alcanzar resultados satisfactorios a una escala de detalle. Así pues, la velocidad del viento podría ser obtenida a partir de modelos disponibles, como las capas calculadas en el Climate Forecast System Reanalysis (CFSR) de la NOAA. Sin embargo, dichos modelos ofrecen una resolución espacial de 12, 20 y $32 \mathrm{~km}^{2}$, lo cual es insuficiente para estudiar la variabilidad de las normales climáticas a escala comarcal. Así quedan como opciones las fórmulas de Tornthwaite, BlaneyCriddle, Turc y Hargreaves-Samani (1985).

Una vez seleccionadas las fórmulas de posible aplicación, se debe seleccionar la más apropiada para la zona de estudio. Los métodos aplicados para seleccionar la fórmula más idónea suelen consistir en el estudio de las correlaciones entre los resultados de las distintas fórmulas y cifras medidas mediante lisímetros. Se puede obtener una buena orientación en un estudio de la ASCE ${ }^{6}$ (Allen et al., 1989), en el que se comparan hasta veinte fórmulas de evapotranspiración bajo los supuestos de humedad relativa media diaria superior o inferior a $60 \%$. Puesto que en los alrededores de la comarca la humedad relativa es elevada,

6. American Society of Civil Engineers (ASCE). 
Tabla 5. Fórmulas más extendidas para el cálculo de la ETP

\begin{tabular}{ll}
\hline Fórmula & Parámetros necesarios \\
\hline Thornthwaite & Temperatura y latitud \\
Blaney-Criddle & Temperatura y latitud \\
Chaumian (1952) & Temperatura, velocidad del viento y humedad relativa \\
Turc (1953) & Temperatura, radiación y humedad relativa \\
Penman (1956) & Evaporación y radiación \\
Grassi-Chirstiansen & Temperatura, radiación y nubosidad \\
Hargreaves (1966) & Temperatura, humedad relativa, velocidad del viento y altitud \\
Penman (1970) & Temperatura, radicación y velocidad viento \\
Hargreaves (1971) & Temperatura, humedad relativa, velocidad viento, radiación y altitud \\
Hargreaves y Samani (1985) & Temperatura y latitud \\
Penman-Monteith (1990) & Temperatura, velocidad del viento, humedad relativa y radiación solar \\
\hline
\end{tabular}

Fuente: elaboración propia a partir de Luís y Cabrera (1995).

se selecciona el primero de los supuestos $(\mathrm{Hr}>60 \%)$. Así pues, las fórmulas seleccionadas reciben un coeficiente de correlación que indica que las más apropiadas son las de Hargreaves-Samani $(0,92)$ y Turc $(0,93)$, resultando peores las de Blaney-Cridle $(0,80)$ y Thornthwaite $(0,77)$. Las diferencias entre Hargreaves-Samani y Turc son difíciles de valorar a partir de estos resultados, pudiéndose emplear cualquiera de las dos. Sin embargo, se ha escogido la fórmula de Turc, ya que se adapta bien a la información disponible. Además, dada su proximidad al mar, la humedad relativa del aire es siempre superior al $50 \%$ en la zona de estudio. Evidentemente, este matiz no se considera en la fórmula de Hargreaves-Samani, motivo principal por el que se ha optado por el método de Turc.

La fórmula propuesta por Turc varía según la humedad, dependiendo de si la humedad relativa media es superior o inferior al 50\%. Para comprobar cuál de las variantes de la fórmula emplear recurrimos de nuevo a los datos de las estaciones automáticas del SIAR (IVIA), y comprobamos que las humedades relativas de las estaciones de la Marina Baja y alrededores son siempre superiores al $50 \%$. Por este motivo la expresión a emplear es...

$$
E T P=0,4 \cdot\left(R_{i}+50\right) \cdot\left(\frac{t}{t+15}\right)
$$

Ecuación 1. Fórmula de Turc (1961), para el cálculo de la ETP, bajo condiciones de humedad relativa elevada.

... donde ETP es la evapotranspiración potencial, en $\mathrm{mm}$; $t$ es la temperatura media del mes, expresada en ${ }^{\circ} \mathrm{C} ; R$ es la radiación solar incidente que alcanza la superficie de la tierra en $\mathrm{cal} / \mathrm{cm}^{2}$. día. En el mes de febrero el coeficiente mensual pasa de 0,4 a 0,37 .

Una vez calculada la fórmula mediante álgebra de mapas para los doce meses se comparan visualmente los resultados con los disponibles de las estacio- 


\section{ETP - Turc}

$\mathrm{mm}$

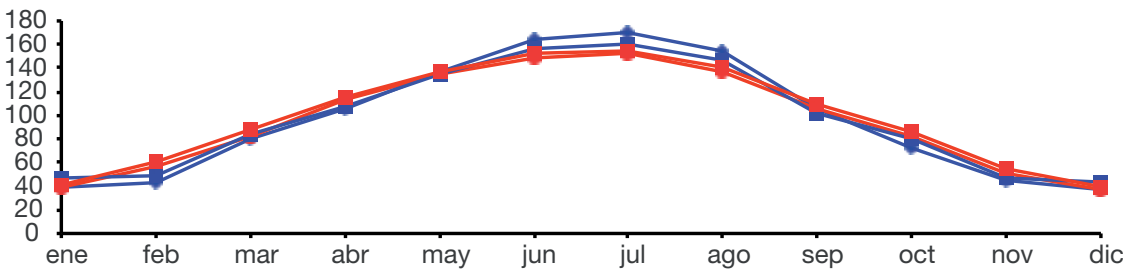

$\multimap$ Altea mont

$\longrightarrow$ Altea turc

$\rightarrow-$ Villajoyosa mont

$\rightarrow-$ Villajoyosa turc

Figura 6. Comparación de la ETP estimada frente a los datos reales.

Fuente: Instituto Valenciano de Investigaciones Agrarias y elaboración propia.

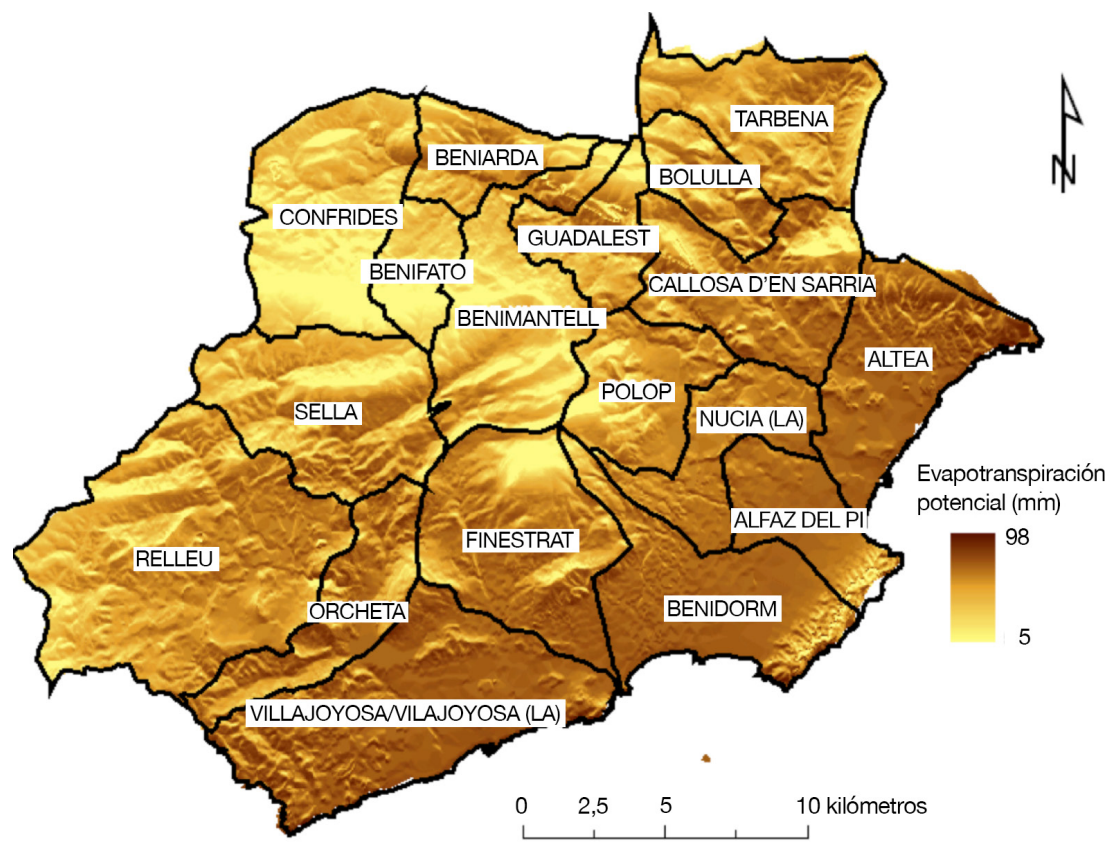

Figura 7. Estimación de la evapotranspiración potencial (ETP) del mes de marzo. Los colores más oscuros indican aquellas zonas de la comarca con una mayor evapotranspiración.

nes automáticas, que están estimados empleando la fórmula de Penman-Monteith (1990). Como se puede comprobar en la Figura 6, el modelo proporciona valores próximos a los de las estaciones automáticas. Sin embargo, resultaría complejo valorar la precisión de los resultados calculándose con datos de orí- 
genes distintos, fórmulas diferentes y series de observación variadas. Además, solamente se cuenta con dos estaciones meteorológicas (Altea y Villajoyosa) que midan la evapotranspiración en la comarca, con lo cual es muy difícil validar el modelo.

A pesar de no poder validar el modelo ETP, las capas generadas aportan una gran cantidad de datos nuevos y describen el componente espacial de la ETP en la comarca. Las posibles fuentes de error son las mismas que en el cálculo de insolación y radiación (escala, usos del suelo y fiabilidad de los registros). Asimismo, el modelo siempre se podría mejorar a partir del uso de imágenes de satélite. En cambio, el uso de análisis de regresión es imposible debido al insuficiente número de estaciones que miden esta variable.

\section{Evapotranspiración de referencia y evapotranspiración del cultivo}

La noción de evapotranspiración de referencia (ETo) es utilizada para reducir las ambigüedades de interpretación a que da lugar el amplio concepto de evapotranspiración. El concepto de ETo es similar al de ETP, ya que ambos dependen exclusivamente de las condiciones climáticas, pero se diferencian en que la ETo se aplica a un cultivo específico o de referencia, habitualmente gramíneas o alfalfa, de 8 a $15 \mathrm{~cm}$ de altura uniforme, de crecimiento activo, que cubre totalmente el suelo y que no se ve sometido a déficit hídrico. La evapotranspiración del cultivo (ETc) es más difícil de calcular que la ETP o ETo, ya que además de las condiciones atmosféricas que influyen en la ETP o ETo, intervienen los requerimientos de los cultivos. Para determinarla se debe corregir la ETP o ETo con un factor Kc dependiente de las características de cada cultivo.

El cálculo de la ETc es un aspecto que suele faltar en los balances hídricos espaciales debido a la dificultad de determinar con cierto detalle los cultivos presentes en amplias extensiones de terreno. La FAO describe el procedimiento de cálculo del Kc de cada cultivo (Allen et al., 1998). La obtención del Kc suele ser un procedimiento arduo, ya que suelen escasear los datos necesarios para su determinación. La mayor parte de aproximaciones del Kc de que se dispone son medias anuales propias de regiones concretas, pero son aproximaciones del todo insuficientes para hacer una buena estimación de las necesidades hídricas en climas semiáridos como el mediterráneo. El Instituto Valenciano de Investigaciones Agrarias (IVIA) ofrece valores del Kc para una gran diversidad de cultivos presentes en la zona de la Marina Baja. Estos pueden consultarse en la aplicación PARlocv $1.2^{7}$.

En la Figura 8.a se puede observar la distribución del Kc durante el ciclo biológico ideal de las plantas, mientras que en la Figura 8.b se han representado los valores mensuales del Kc de tres de los cultivos más representativos de la comarca. Un simple vistazo basta para percibir que los cítricos tienen necesidades relativamente altas durante todo el año, los nísperos precisamente reducen

7. Aplicación informática gratuita «PARloc» del Programa de asesoramiento para riego localizado, del Servicio de Tecnología del Riego de la Generalitat Valenciana. 

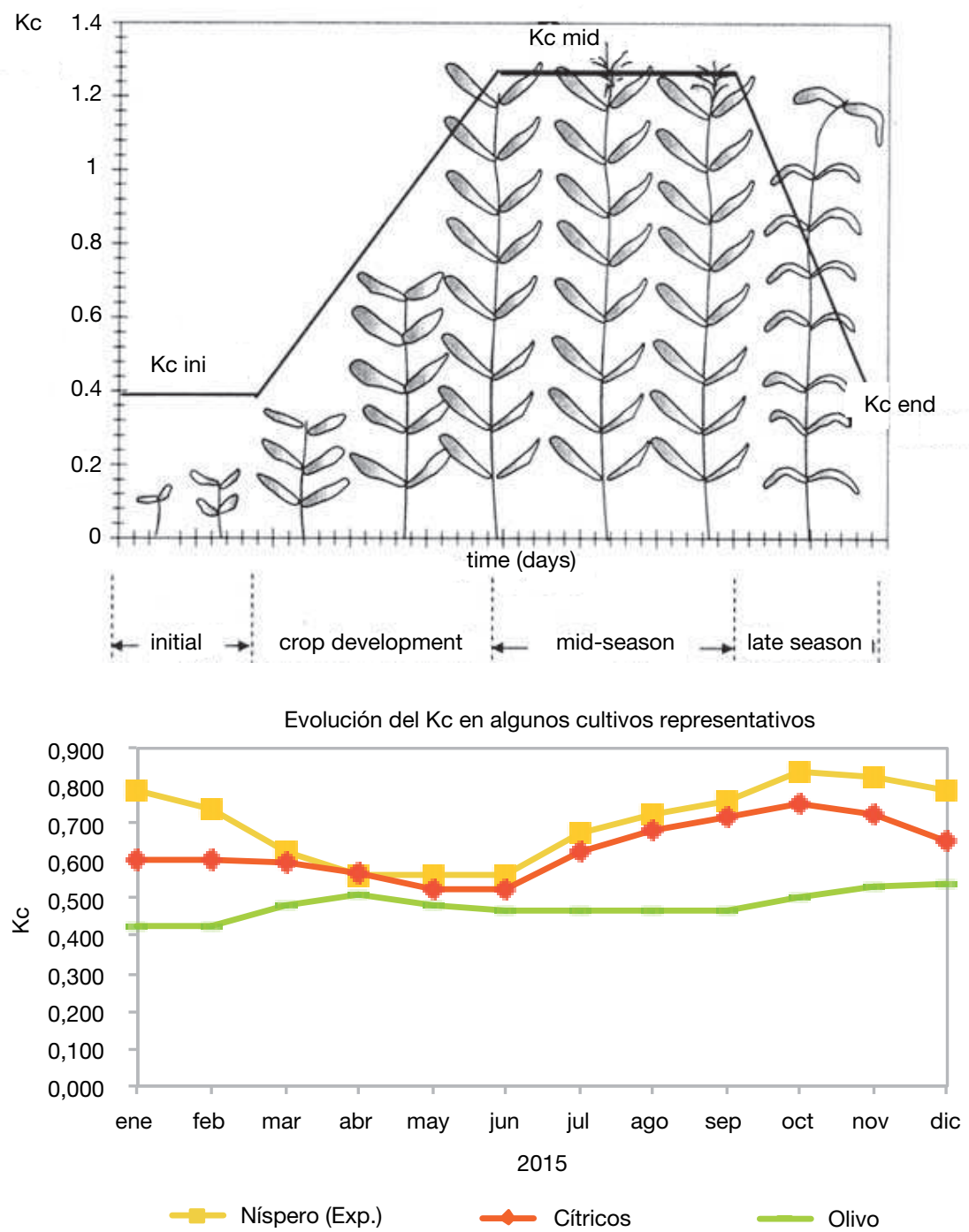

Figura 8. a) Curva generalizada de coeficiente de cultivo Kc. Fuente: Estudios FAO Riego y Drenaje $n^{\circ} 56 ; b$ ) Coeficientes de cultivo de algunos cultivos presentes en la Comarca.

Fuente: IVIA.

las necesidades en verano y los olivos mantienen sus necesidades durante todo el año, siendo estas no demasiado elevadas. Reviste especial interés el comentario respecto a las necesidades del níspero, debido a que en verano es cuando más patentes se hacen los efectos de las sequías. Se puede interpretar que el cultivo del níspero no ejerce competencia por los recursos hídricos en verano, 
pudiendo emplear mayor volumen para los abastecimientos humanos (Rico y Olcina, 2004).

Una vez se dispone de los respectivos Kc se procede al cálculo de la ETc. Se introducen los valores de Kc correspondientes en la base de datos espacial donde se habrá realizado la interpretación de los usos del suelo y donde se distinguen los distintos cultivos. Estos valores son los que se debe multiplicar por la ETP mensual que se ha calculado en el apartado anterior, obteniendo así una matriz raster que representa la evapotranspiración del cultivo.

\section{Evapotranspiración real y balance hidrico}

Los conceptos anteriores (ETP, ETo y ETc) presuponen que no existen limitaciones de ningún tipo en el desarrollo de los cultivos, ya sean edáficos, climáticos, de plagas o malezas de las plantas. Sin embargo, en la realidad el medio natural puede no cubrir las necesidades de las plantas. La aproximación más simple al cálculo de la evapotranspiración real (ETr) es mediante la diferencia que en un periodo de tiempo se produce entre las precipitaciones y la ETP. Así, para aproximarse más a la realidad del balance hídrico se debe contar con las precipitaciones, la evapotranspiración (ETP, ETo o ETc) y la capacidad de retención del suelo, que se determina mediante los análisis físico-químicos correspondientes, o utilizando algunas cifras aproximadas.

La capacidad de retención del suelo varía espacialmente según distintos factores que se pueden estimar analíticamente (p. ej. textura, contenido en materia orgánica, etc.). Actualmente, se ha iniciado la elaboración de un «mapa de agua disponible en el suelo» en la Marina Baja. Se ha realizado un amplio muestreo de la comarca (50 muestras), localizando con GPS los puntos analizados, y se espera que en breve se pueda llevar a cabo un estudio geoestadístico que permita la creación de este mapa y de otros relacionados con el potencial nutritivo del suelo.

Así pues, para suplir esta carencia en el presente estudio se toma una cifra aportada por Thornthwaite (1948), que indica que para un suelo arcilloso en el que hay cultivados árboles frutales, la capacidad de retención máxima sería de $200 \mathrm{~mm}$. Se toma esta capacidad de retención sabiendo que esta cifra puede ser incluso mayor, de hasta $250 \mathrm{~mm}$ para suelos franco-arcillosos, los cuales a priori son los predominantes en la zona de estudio (Quereda Sala, 1978). La estimación de Thornthwaite no tiene en cuenta aspectos clave como la compactación del suelo, que no han tenido relevancia hasta recientemente, con el incremento del abandono de ciertas prácticas agrícolas (Zaragozí, 2012).

La realización del balance hídrico en el suelo se lleva a cabo mediante el método de la ficha hídrica planteada por Thornthwaite. Este método plantea, en principio, cierta dificultad cuando se aplica espacialmente, para ello se han planteado distintas fórmulas que simplifican en gran medida las tareas a realizar. Una vez hechas las consideraciones anteriores se calcula el balance hídrico mes a mes mediante las operaciones de álgebra de mapas propuestas en la Tabla 6. Se entiende que el balance comienza al final del verano (septiembre), 
Tabla 6. Fórmulas propuestas para el cálculo del balance hídrico

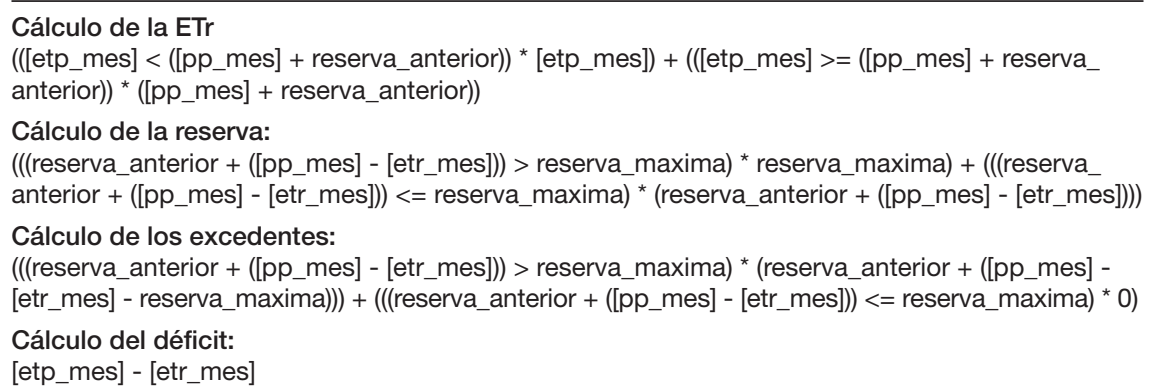

$\overline{\mathrm{ETP}}=$ evapotranspiración potencial; $\mathrm{pp}=$ precipitación; $\mathrm{ETr}=$ evapotranspiración real; reserva = reserva hídrica.

Fuente: elaboración propia.

cuando la reserva en el suelo está agotada, de modo que a partir de las primeras lluvias comenzará la reconstrucción de la reserva.

Estas operaciones simplifican al máximo los cálculos del balance, reduciendo la necesidad de capas intermedias y facilitando asimismo la creación de scripts para la automatización de las tareas. Como resultado de las múltiples operaciones se obtienen doce capas raster mensuales para cada una de las fórmulas propuestas (ETr, déficit, reserva y superávit).

La estación meteorológica de Callosa d'en Sarrià es la única que cuenta con observaciones de temperaturas y precipitaciones completas para una serie de más de treinta años, por lo que es habitual que se utilice esta estación para los cálculos de balance hídrico de la comarca. En la Figura 9 se distinguen las etapas temporales por las que discurre el balance hídrico medio en el municipio de Callosa d'en Sarrià. El balance hídrico puntual se refiere a la localización de la estación meteorológica, mientras que el balance hídrico espacial se refiere a datos medios obtenidos a partir de los resultados del modelo para todo el municipio.

En la Figura 9 se ha realizado una comparación entre el balance hídrico tradicional (puntual de un observatorio) y el balance hídrico espacial del municipio de Callosa d'en Sarrià para poder apreciar más fácilmente las importantes diferencias que el sesgo espacial ha introducido tradicionalmente en el conocimiento que se tenía de los recursos. Se observan diferencias importantes en todas las variables relacionadas debido a que las cifras del observatorio de Callosa d'en Sarrià no pueden ser representativas de toda la extensión del municipio, el cual discurre entre una zona montañosa más lluviosa y los fondos de valle más cálidos. El resultado del balance hídrico espacial plasma mejor las necesidades de agua de los cultivos y de la vegetación natural. El dato más llamativo que se extrae de esta comparativa es que la reserva hídrica del municipio se agota más rápidamente, hasta dos meses antes de lo que se puede estimar a partir de un balance hídrico puntual. Además, resulta interesante el cálculo del balance hídrico sobre el de otros índices fitoclimáticos, pues introduce una resolución temporal agregada 

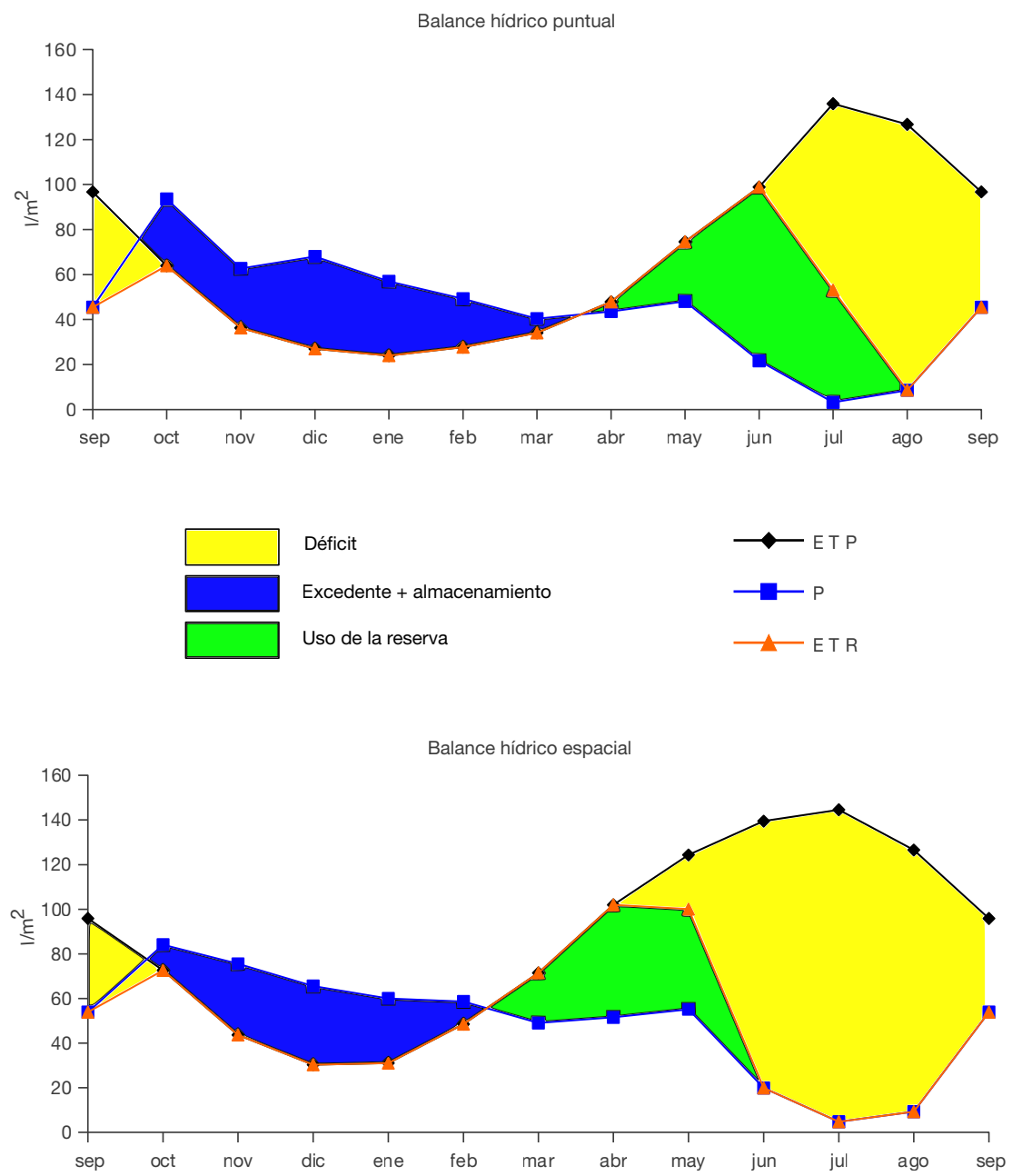

Figura 9. Comparación de los valores de un balance hídrico puntual (tradicional), frente a los del balance hídrico espacial, en el municipio de Callosa d'en Sarrià.

Fuente: los datos del balance puntual pertenecen Pérez Cueva (1991). Elaboración propia.

por meses. Dichos índices solamente emplean algunas cifras significativas para caracterizar las potencialidades del territorio, y habitualmente dan resultados poco acordes con la realidad, a no ser que se den ciertas correcciones (Benavides et al., 2009). Finalmente, en la Figura 10 se aporta una clasificación en la que se diferencian cinco zonas representativas del estado medio del balance hídrico. Se trata de una zonificación provisional, que se modificará sustancialmente de acuerdo con la variación de los usos del suelo y de las características de los suelos. El método para realizar la clasificación parte de un Análisis de Componentes 


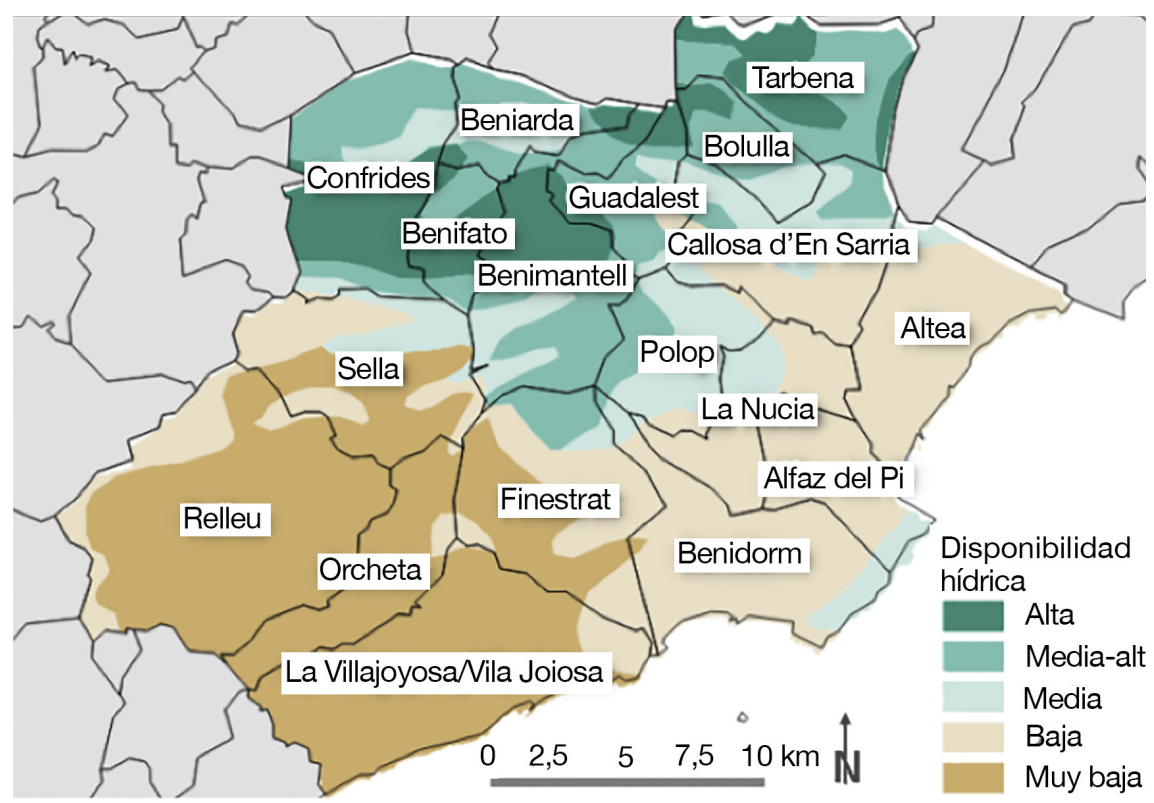

Figura 10. Síntesis de las disponibilidades hídricas de la Marina Baja, según el balance hídrico espacial.

Fuente: elaboración propia.

Principales (APC), aplicado sobre los rasters mensuales de reservas hídricas, que se han calculado en los apartados anteriores. A continuación, aplica un algoritmo Isocluster, disponible también en distintos software SIG, para analizar las características de agrupamiento de los píxeles de las capas obtenidas mediante el APC, y por último se realiza una clasificación por el método de máxima verosimilitud (Maximum Likehood). Se trata de una clasificación no supervisada basada en métodos probabilísticos y matemáticos que se ajusta a los conocimientos previos que teníamos del clima de la zona. Una vez obtenida dicha clasificación, se ha elaborado una generalización cartográfica para mejorar la comprensión de los resultados. En estas zonas se distinguen claramente las diferencias entre los valles de los ríos Guadalest-Algar y Amadorio-Sella, debidas fundamentalmente a la mayor pluviosidad al norte del eje montañoso de Aitana, además se distinguen las diferencias hídricas entre las solanas y las umbrías. Probablemente, esta representación pueda matizarse incorporando datos de observatorios litorales, a pesar de que aún no cuenten con series temporales suficientes.

\section{Discusión}

Tras unas primeras reflexiones sobre el estado de los estudios de balance hídrico, se ha visto una clara preferencia por abandonar los análisis puntuales 
tradicionales de estaciones meteorológicas, tendiendo a incorporar el sentido espacial en este tipo de estudios fundamentalmente a través del análisis de imagen de satélite, pero también mediante el uso de técnicas geoestadísticas. Por otro lado, también se destaca el uso de sensores más precisos y tecnológicamente avanzados como los empleados por la NASA (Quickscat, Grace o TRMM), para observar todos los procesos del ciclo hidrológico. A pesar de existir propuestas tan interesantes como estas, son todas aún poco ágiles y difícilmente operativas, ya que resultan necesarias diversas fuentes de datos no siempre disponibles a nivel local, y en todo caso es preciso el tratamiento de dichas imágenes por personal especializado. Puesto que no existe un servicio similar que cubra la zona de estudio, se ha estimado que es necesario disponer de un método, ágil y operativo, para la estimación de las disponibilidades hídricas distribuidas por el territorio y la rápida incorporación de todas las capas creadas a un análisis KDD. Para ello se ha ensayado una metodología SIG que estima el balance hídrico superficial de la comarca, con decenas de capas intermedias, y se comprueba que se puede producir información con una calidad y unos plazos aceptables, aspectos estos, esenciales en estudios KDD.

El caso aquí planteado ha consistido en el estudio de medias mensuales, pero igualmente se trata de herramientas que permitirían tratar periodos más concretos o incluso de resolución temporal diaria mediante el complemento de imagen de satélite que pudiera estar disponible. Por lo tanto, no hay que descartar el uso de información climática a una escala local o intermedia en cualquier estudio basado en la metodología KDD, la única limitación vendría impuesta por los datos accesibles.

La metodología planteada para elaborar el balance hídrico espacial busca un equilibrio entre el detalle de los datos y su inmediatez. Como se ha mencionado anteriormente, este análisis podrá ser mejorable en varios aspectos. El cálculo de las capacidades de retención de los suelos, matizando las infiltraciones y la evapotranspiración según los distintos usos del suelo y tipos de cultivo, o también la mejora de los distintos modelos climáticos intermedios conducentes a elaborar el balance hídrico. Además, estos estudios se volverían más habituales si organismos como AEMET facilitasen esta información de manera abierta, mediante protocolos estándar de intercambio de datos.

Las 84 capas SIG derivadas de datos climáticos fueron utilizadas en un primer experimento de Minería de Datos espacial basado en reglas de clasificación para determinar las variables relacionadas con el abandono agrícola en la Marina Baja (Zaragozí, 2012) y aunque el análisis fue capaz de destacar algunas variables como las precipitaciones medias en el mes de enero, queda evidenciado el hecho de que el clima no es un factor limitante que pueda explicar el abandono por sí mismo. Ciertamente, no se esperaba ninguna relación destacada entre clima y abandono para la Marina Baja, pero los resultados obtenidos han ayudado a plantear, de un modo ágil, nuevas hipótesis de trabajo y determinar la necesidad de adquirir nuevos datos climáticos para ciertas épocas del año o áreas de la zona de estudio. 


\section{Referencias bibliográficas}

Allenn, Richard G.; Jensen, Marvin E.; Wright, James L.; Burman y Richard D. (1989). «Operational Estimates of Reference Evapotranspiration». Agronomy Journal, 81, 650-662. <http://dx.doi.org/10.2134/agronj1989.00021962008100040019x>

Allen, Richard G.; Pereira, Luis S.; Raes, Dirk y Smith, Martin (1998). Crop evapotranspiration - guidelines for computing crop water requirements. Nueva York: FAO.

Andreu, Joaquín J.; Capilla, José E. y Sanchis, Emilio (1996). «AQUATOOL, a generalized decision-support system for water-resources planning and operational management». Journal of Hidrology, 177, 269-291.

Benavides, Raquel; Roig, Sonia y Osoro, Koldo (2009). «Potential productivity of forested areas based on a biophysical model. A case study of a mountainous region in northern Spain». Annals of Forest Science, 66, 108. $<$ http://dx.doi.org/10.1051/forest/2008080>

Camp, R. J. y Wheaton, J. M. (2014). «Streamlining field data collection with mobile apps». Eos, Transactions American Geophysical Union, 95 (49), 453-472

Dripps, Weston R. y Bradbury, Ken R. (2007). «A simple daily soil-water balance model for estimating the spatial and temporal distribution of groundwater recharge in temperate humid areas». Hydrogeology Journal, 15, 433-444. $<$ http://dx.doi.org/10.1007/s10040-007-0160-6>

Elwood, Sarah; Goodchild, Michael F. y Sui, Daniel Z. (2014). «Researching Volunteered Geographic Information: Spatial Data, Geographic Research, and New Social Practice». Annals of the Association of American Geographers, 3, 571-590. $<$ http://dx.doi.org/10.1080/00045608.2011.595657>

Gibert, Karina y SAnchez-Marrè, Miquel (2011). «Outcomes from the iEMSs data mining in the environmental sciences workshop series». Environmental Modelling \& Software, 26, 983-985. $<$ http://dx.doi.org/10.1016/j.envsoft.2011.01.009>

Google (2011). Google Achieves Search Milestone With Immediate Access To More Than 6 Billion Items. Google Press Cent 1.

Liv, W. Timothy; Xie, Xiaosu; Tang, Wenquing y Zlotnicki, Victor (2006). «Spacebased observations of oceanic influence on the annual variation of South American water balance». Geophysical Research Letters, 33, L08710. $<$ http://dx.doi.org/10.1029/2006GL025683>

Luis romero, Arturo (1995). «Formulación de los modelos matemáticos para la determinación de los principales elementos que intervienen en el cálculo del régimen de riego en caña planta». Caña de Azúcar, 13 (01), 3-22.

Maimon, Oded y Rokach, Lior (2010). Data Mining and Knowledge Discovery Handbook. Nueva York: Springer.

Ninyerola, Miquel; Pons, Xavier y Roure, Joan M. (2000). «A methodological approach of climatological modelling of temperature and precipitation through GIS techniques». International Journal of Climatology, 20 (14), 1823-1841.

Parker, Dawn C.; Hessl, Amy y Davis, Sarah C. (2008). "Complexity, land-use modeling, and the human dimension: Fundamental challenges for mapping unknown outcome spaces». Geoforum, 39, 789-804. $<$ http://dx.doi.org/10.1016/j.geoforum.2007.05.005>

Pérez Cueva, Alejandro J. (1991). Atlas climàtic de la Comunitat Valenciana, 19611990. València: Conselleria d’Obres Públiques, Urbanisme i Transports. 
Quereda Sala, José (1978). Comarca de La Marina, Alicante: estudio de geografía regional. Alicante: Excma. Diputación Provincial.

Reed, Seann. M.; Maidment, David. R. y Patoux, Jérome (1997). «Spatial Water Balance of Texas». Online Report, 97-1. Disponible en: <http://www.ce.utexas. edu/prof/maidment/gishydro/seann/texas/wbtexas.htm>.

Rico Amorós, Antonio y Olcina Cantos, Jorge (2004). «El abastecimiento de agua en la Marina Baja (Alicante): Un ejemplo de complementariedad entre usos agrarios y urbano-turísticos». En: Historia clima y paisaje. Estudios geográficos en Memoria del Profesor Antonio López Gómez. Universitat de València, 551-567.

Ruíz, José Manuel (1998). «Desarrollo de un modelo hidrológico conceptual distribuido de simulación continua integrado con un SIG». Universidad Politécnica de Valencia.

Sánchez Montahud, Juan Rafael; Eisenhuth, Denise; Bellot Abad, Juan, et al. (2004). "Los vínculos existentes entre los recursos hídricos y la sostenibilidad de los sistemas naturales y humanos en la Marina Baixa». IV Congreso Ibérico sobre Gestión y Planificación del Agua. Tortosa, 8-12. Disponible en: <http://rua.ua.es/ dspace/handle/10045/25878>

Thornthwaite, Charles Warren (1948). "An approach toward a rational classification of climate». Geographical Review, 38, 55-94.

Turc, L. (1967). «Incidence des facteurs macroclimatiques sur les productions végétales». Fourrages, 31.

Wilson, John P. y Gallant, John C. (2001). Terrain Analysis. Principles and Applications. Nueva York: John Wiley \& Sons.

Xu, Xiaowei; Ester, Martin; Kriegel, Hans-Peter y Sander, Jörg (1998). «A distribution-based clustering algorithm for mining in large spatial databases». En: Proceedings 14th International Conference on Data Engineering. IEEE Computer Society Technical Committee on Data Engineering, 324-331.

Zaragozí, Benito Manuel; Rabasa, Alejandro; Rodríguez-sala, Jesús Javier, et al. (2012). "Modelling farmland abandonment: A study combining GIS and data mining techniques». Agriculture, Ecosystems \& Environment, 155, 124-132. <http://dx.doi.org/10.1016/j.agee.2012.03.019> 